\title{
Impact of Change in the Price of Percutaneous Coronary Intervention Devices on Medical Expenses
}

\author{
Nakabumi Kuroda, MD; Yoshio Kobayashi, MD*; Kartik Desai, MD*; \\ Costantino Costantini, MD*; Mika Kobayashi, RN*; Issei Komuro, MD**
}

\begin{abstract}
Percutaneous coronary intervention (PCI) devices are much more expensive in Japan than in the United States, but their prices were reduced in April 2002. This study evaluated the impact of that change in the price of PCI devices on medical expenses. In-hospital costs of 22 consecutive patients who underwent elective single-vessel PCI without a debulking procedure before April 2002 were collected and the in-hospital cost of each patient was recalculated by applying the current prices of the PCI devices and those in the USA. For patients treated with PCI before April 2002, the in-hospital cost was $¥ 1,456,375 \pm 358,781$, but when the current price is used, the in-hospital cost is estimated to be $¥ 1,355,812 \pm 313,237$ ( $7 \%$ reduction). If the prices of the devices were reduced to those in USA, there would be a 53\% reduction $(¥ 689,417 \pm 99,139)$. Although the change in the price of PCI devices in April 2002 has reduced in-hospital costs, the devices are still much more expensive in Japan than in the USA. Further reduction of the price is required to make PCI more cost-effective. (Circ J 2003; 67: 576-578)
\end{abstract}

Key Words: Angioplasty; Cost analysis; Stent

B ecause of the prolonged recession, structural reform has been implemented in Japan and the Government sponsored, Japanese health insurance system has not been exempted. Heated debate on reform of the medical insurance system was held in the last Diet session. Because of increasing medical expenses as a result of the growing elderly population, the medical insurance system is mired in red ink, with almost all health insurance associations currently in the red. In this situation, physicians must be more cost-conscious, but little attention has been paid to cost analysis in Japan!

It has been known for a long time that medical devices are much more expensive in Japan than in the United States (USA) $)^{1-7}$ so in April 2002 the prices of medical devices, such as pacemaker and percutaneous coronary intervention (PCI) devices, were reduced, in an attempt to save medical expenses. This study evaluated the impact of that change in the price of PCI devices on medical expenses.

\section{Methods}

The in-hospital costs of 22 consecutive patients who underwent elective single-vessel PCI without debulking procedure at Sawara Hospital in Chiba, Japan before April 2002 were collected. Coronary stenting was performed in 18 of the 22 patients and procedural success was achieved in all patients except 1 with chronic total occlusion. There were no major in-hospital complications. Non-Q-wave

(Received December 26, 2002; revised manuscript received March 28, 2003; accepted April 8, 2003)

Department of Internal Medicine, Sawara Hospital, Chiba, Japan, **Cardiovascular Research Foundation, Lenox Hill Heart and Vascular Institute, New York, NY, USA and ***Department of Cardiovascular Science and Medicine, Chiba University Graduate School of Medicine, Chiba, Japan

Mailing address: Yoshio Kobayashi, MD, Cardiovascular Research Foundation, Lenox Hill Heart and Vascular Institute, New York, NY 10022, USA. E-mail: ykobayashi@crf.org myocardial infarction occurred in 1 patient. None had a vascular complication that required a longer hospital stay. When patients had other diseases such as diabetes mellitus, the medical cost of those diseases was excluded. Changes in the technique of PCI and modification of the devices affect catheterization laboratory resource utilization, and subsequently in-hospital cost. To evaluate the pure reduction of in-hospital cost by a change in the prices of the PCI devices catheterization laboratory resource utilization, such as the number of balloon catheters and stents used, must be the same. Thus we recalculated the in-hospital cost of each patient by applying the current prices of PCI devices! In addition, to evaluate the difference in the in-hospital cost between Japan and USA because of the different prices of the PCI devices, it was recalculated using the USA prices $(\$ 1=¥ 120)^{2-4}$

\section{Results}

In patients treated by PCI before April 2002, the in-hospital cost was $¥ 1,456,375 \pm 358,781$. The costs of PCI and PCI devises were $¥ 1,314,159 \pm 357,301$ and $¥ 1,069,819 \pm$ 357,010 , respectively, which were $90 \%$ and $73 \%$ of the total in-hospital cost. Table 1 presents the number of devices used, previous and current prices of PCI devices in Japan and those in the USA. When the current prices of PCI devices are used in the recalculation of the in-hospital cost of those patients, there is a 7\% reduction (ie, in-hospital cost $=¥ 1,355,812 \pm 313,237)$. The cost of the PCI device is $¥ 935,256 \pm 311,494$ (13\% reduction). If the prices of the devices were reduced to those in USA, in-hospital and PCI device costs would be $¥ 689,417 \pm 99,139$ (53\% reduction) and $¥ 268,861 \pm 96,534$ (75\% reduction), respectively.

\section{Discussion}

Because of snowballing medical expenses in an aging society, the nation's health insurance system is on the verge 
Table 1 Catheterization Laboratory Resource Utilization, Unit Cost and Procedural Fee for-PCI

\begin{tabular}{|c|c|c|c|c|c|c|c|}
\hline & No. of devices used & Previous cost & Current cost & $\begin{array}{c}\text { United States } \\
(\$ 1=¥ 120)\end{array}$ & $\begin{array}{l}\text { United Kingdom } \\
\quad(£ 1=¥ 187)\end{array}$ & $\begin{array}{l}\text { the Netherlands } \\
\text { (1 euro }=¥ 126 \text { ) }\end{array}$ & $\begin{array}{l}\text { Argentine } \\
(\$ 1=¥ 120)\end{array}$ \\
\hline Stent & $1.0 \pm 0.6$ & $¥ 338,000$ & $¥ 324,000$ & $\begin{array}{l}¥ 126,000 \\
(\$ 1,050)^{*}\end{array}$ & $\begin{array}{c}¥ 108,834 \\
(£ 582)\end{array}$ & $\begin{array}{l}¥ 102,942 \\
\text { (817 euro) }\end{array}$ & $\begin{array}{c}¥ 360,000 \\
(\$ 3,000)\end{array}$ \\
\hline Balloon catheter & $1.7 \pm 0.8$ & $¥ 263,000^{* *}$ & $¥ 197,000$ & $\begin{array}{l}¥ 34,800 \\
(\$ 290)\end{array}$ & $\begin{array}{r}¥ 36,652 \\
(£ 196)\end{array}$ & $\begin{array}{l}¥ 46,368 \\
\text { (368 euro) }\end{array}$ & $N A$ \\
\hline Intravascular ultrasound & $0.8 \pm 0.4$ & $¥ 219,000$ & $¥ 214,000$ & $\begin{array}{l}¥ 55,200 \\
(\$ 460)\end{array}$ & $N A$ & $\begin{array}{l}¥ 68,670 \\
\text { (545 euro) }\end{array}$ & $N A$ \\
\hline Guidewire (0.014") & $1.7 \pm 0.9$ & $¥ 32,700^{\dagger}$ & $¥ 30,800$ & $\begin{array}{l}¥ 12,000 \\
(\$ 100)\end{array}$ & $\begin{array}{c}¥ 11,220 \\
(£ 60)\end{array}$ & $\begin{array}{l}¥ 11,970 \\
\text { (95 euro) }\end{array}$ & $N A$ \\
\hline Guiding catheter & $1.3 \pm 0.6$ & $¥ 39,900^{\dagger \dagger}$ & $¥ 38,000$ & $\begin{array}{l}¥ 6,240 \\
(\$ 52)\end{array}$ & $\begin{array}{r}¥ 6,732 \\
(£ 36)\end{array}$ & $\begin{array}{c}¥ 10,332 \\
\text { (82 euro) }\end{array}$ & $N A$ \\
\hline Procedural fee & - & $¥ 205,000 \div ¥ 199,000^{\#}$ & $¥ 239,000$ & $N A$ & $N A$ & $N A$ & $N A$ \\
\hline
\end{tabular}

PCI, percutaneous coronary intervention. *Average price of the Penta, BX Belocity, NIR, and S7 stent. **general I, ${ }^{\dagger}$ standard II, ${ }^{\dagger}$ standard I, ${ }^{\ddagger}$ conventional balloon angioplasty, and ${ }^{\#}$ stenting. NA, not available or applicable (the procedural fee in the US was not used to recalculate the in-hospital cost).

of financial crisis. Medical expenses in Japan increased from 20 trillion yen in the fiscal year 1989 to 31 trillion yen in the fiscal year 1999 (the statistical reports of the Health, Labor and Welfare Ministry in Japan). More than 1,700 corporate insurance societies are making losses, the combined total of which is likely to amount to 500 billion yen this fiscal year. Heated discussion was held in the last Diet session, and reforms of the medical insurance system, such as increase in a salaried worker's payment for a medical expense and a decrease in medical insurance reimbursements, were decided. However, it might be difficult to improve the economic situation of the insurance system and thus fundamental reform of the medical insurance system may be inevitable. In that situation, physicians are required to be more cost-conscious and to treat patients efficiently, although there must not be any impairment of quality of care. Although considerable attention has been paid to cost analysis in the $\mathrm{USA}^{2-7}$ it has not been fully discussed in Japan!

Increasing demand for PCI is placing a large financial burden on limited healthcare resources. The Japanese Coronary Intervention Study Group conducted a nationwide survey on coronary revascularization procedures during 1997 and reported that a total of 109,788 PCI and 17,667 coronary artery bypass procedures were performed in Japan? The ratio of PCI to coronary artery bypass surgery was 6.2 , which is much higher than in the USA? Thus reduction in the cost of PCI in Japan, especially of the PCI device, which constitutes $73 \%$ of the total in-hospital cost, is important. Even though some of patients may have multivessel coronary intervention, it can be roughly estimated that the change in the prices of PCI devices in April 2002 saves $¥ 11$ billion/year $¥ ¥(1,456,375-1,355,812) \times 109,788]$.

PCI devices are much more expensive in Japan than in USA or Europe (Table 1),-4,9,10 and although the change in the prices in April 2002 reduces the gap slightly, the devices are still much expensive in Japan, even though most are imported. If the prices were reduced to those in the USA, it would save medical expenses of $¥ 73$ billion/year [¥$(1,355,812-689,417) \times 109,788]$. The numbers of balloon catheters and stents for reimbursement have been less since April 2002, but there are cases with complex lesions that require more devices. If the prices of the devices were reduced to those in the USA, we might be allowed to use the devices as required. Deregulation of the competition in the interventional products is necessary to reduce stent and angioplasty equipment prices.
It has been reported that the difference in overall (inhospital+follow-up) cost between conventional balloon angioplasty and stenting would be $¥ 74,016$ in the USA ( $¥ 1,098,807$ vs $¥ 1,172,823$ ), whereas it is $¥ 375,655$ in Japan (¥1,188,583 vs ¥1,564238)! Few modern medical advances are truly cost-saving, and many wide-spread practices, including bypass surgery for left main disease ${ }^{11}$ $\beta$-blocker therapy after acute myocardial infarction ${ }^{12}$ and thrombolytic therapy for acute myocardial infarction ${ }^{13}$ prolong life only at the expense of increased healthcare costs. Nevertheless, such treatments are viewed as costeffective because their benefits to the patient are "worth the additional cost'. From this viewpoint, stenting is considered to be 'worth the additional cost' $¥ 74,016)$ in the USA, but the cost difference in Japan ( $¥ 375,655$ ) may be too high for such justification. Recently, a dramatic reduction in the rate of restenosis has been demonstrated with drug-eluting stents ${ }^{14}$ The projected cost of a drug-eluting stent is likely to be approximately $\$ 3,200$, which is almost 3-fold more expensive than a bare stent $1^{15}$ Thus it might cost one million yen in Japan and all patients might not be able to receive the benefit of drug-eluting stents.

Recent randomized studies demonstrated long-term outcomes in patients with multivessel disease treated with multivessel stenting compared with CABG ${ }^{16-18}$ The longterm mortality was controversial, although target revascularization rates were higher in the stent group than in the surgery group ${ }^{16-18}$ Cost analysis of multivessel stenting and coronary bypass surgery in the USA and Europe showed a lower overall (in-hospital and follow-up) cost in the stent group 16,19 but a study in Argentine where stenting is much more expensive $(\$ 3,000)$ than in the USA and Europe, as in Japan, demonstrated no difference in the overall cost between the 2 techniqes! ${ }^{17}$

There has been a comparison of the long-term outcome of medical therapy and PCI, particularly in patients with single-vessel disease, which showed that long-term mortality, myocardial infarction, and target lesion revascularization were similar between the 2 therapy groups, but that PCI was superior to medical treatment for the alleviation of angina ${ }^{20}$ Overall cost was less in the medical therapy group than in the PCI group? Thus, particularly in the face of constraints on healthcare spending, it may be recommended that physicians reserve PCI for patients with single-vessel disease whose symptoms of angina are not well controlled by medical treatment? ${ }^{2}$

Because of the Government sponsored, Japanese health 
insurance system, all Japanese citizens are able to receive the best treatment equally. However, the nation's health insurance system is on the verge of a financial crisis and so physicians must be more cost-conscious, and furthermore everyone in Japan must consider reforms to the medical insurance system. Otherwise physicians may not be able to provide the best treatment for all patients equally.

\section{Study Limitations}

The in-hospital cost of patients treated before April 2002 was recalculated by applying the current device prices and those in the USA to estimate those after the change in the prices and in USA. The difference in catheterization laboratory resource utilization affects in-hospital cost. Furthermore, the method of calculating in-hospital cost and the reimbursement system are completely different between Japan and the USA $!^{-7}$ That is why we used this method to evaluate the pure difference in the in-hospital cost because of the different device prices! Reimbursement prices of the devices were used to calculate the in-hospital cost in Japan. On the other hand, market prices are used in the USA, because there are no reimbursement prices. Thus the difference in the prices of the PCI devices may be less; however, even considering this possible disagreement, PCI devices are much more expensive in Japan!

\section{Conclusions}

The change in the prices of PCI devices in April 2002 reduces the in-hospital cost by $7 \%$. However, the devices are still much more expensive in Japan than in USA and further reduction of the prices is required to make PCI more cost-effective.

\section{References}

1. Kobayashi Y, De Gregorio J, Yamamoto Y, Komiyama N, Miyazaki A, Masuda Y. Cost analysis between stent and conventional balloon angioplasty. Jpn Circ J 2000; 64: 161 - 164.

2. Cohen DJ, Taira DA, Berezin R, Cox DA, Morice MC, Stone GW, et al. Cost-effectiveness of coronary stenting in acute myocardial infarction: Results from the stent primary angioplasty in myocardial infarction (stent-PAMI) trial. Circulation 2001; 104: 3039-3045.

3. No authors listed. Stent prices expected to decline. Hosp Mater Manage 2001; 26: 1, 12-13.

4. Choi JW, Goodreau LM, Davidson CJ. Resource utilization and clinical outcomes of coronary stenting: A comparison of intravascular ultrasound and angiographical guided stent implantation. Am Heart $J$ 2001; 142: 112-118.

5. Cohen DJ, Krumholz HM, Sukin CA, Ho KKL, Siegrist RB, Cleman $\mathrm{M}$, et al. In-hospital and one-year economic outcomes after coronary stenting or balloon angioplasty: Result from a randomized clinical trial. Circulation 1995; 92: 2480-2487.
6. Cohen DJ, Breall JA, Ho KKL, Weintraub RM, Kuntz RE, Weinstein MC, et al. Economics of elective coronary revascularization: Comparison of costs and charges for conventional angioplasty, directional atherectomy, stenting and bypass surgery. J Am Coll Cardiol 1993; 22: 1052-1059.

7. Cohen DJ, Breall JA, Ho KKL, Kuntz RE, Goldman L, Baim DS, et al. Evaluating the potential cost-effectiveness of stenting as a treatment for symptomatic single-vessel coronary disease: Use of a decision-analytic model. Circulation 1994; 89: 1859-1874.

8. Shihara M, Tsutsui H, Tsuchihashi M, Shigematsu H, Yamamoto S, Koike G, et al. Coronary revascularization in Japan. Jpn Circ J 2001; 65: $1005-1010$.

9. Sculpher MJ, Smith DH, Clayton T, Henderson RA, Buxton MJ, Pocock SJ, et al. Coronary angioplasty versus medical therapy for angina: Health service costs based on the second Randomized Intervention Treatment of Angina (RITA-2) trial. Eur Heart J 2002; 23: $1291-1300$.

10. Serruys PW, de Bruyne B, Carlier S, Sousa JE, Piek J, Muramatsu T, et al. Randomized comparison of primary stenting and provisional balloon angioplasty guided by flow velocity measurement: Doppler Endpoints Balloon Angioplasty Trial Europe (DEBATE) II Study Group. Circulation 2000; 102: 2930-2937.

11. Weinstein MC, Stason WB. Cost-effectiveness of coronary artery bypass surgery. Circulation 1982; 66(Suppl III): III-56-III-66.

12. Goldman L, Sia STB, Cook EF, Rutherford JD, Weinstein MC. Costs and effectiveness of routine therapy with long-term betaadrenergic antagonists after acute myocardial infarction. $N$ Engl $J$ Med 1988; 319: $152-157$.

13. Krumholz HM, Pasternak RC, Weinstein MC, Friesinger GC, Ridker PM, Tosteson ANA, et al. Cost effectiveness of thrombolytic therapy with streptokinase in elderly patients with suspected acute myocardial infarction. N Engl J Med 1992; 327: 7-13.

14. Morice MC, Serruys PW, Sousa JE, Fajadet J, Ban Hayashi E, Perin $\mathrm{M}$, et al. Randomized study with the sirolimus-coated Bx velocity balloon-expandable stent in the treatment of patients with de novo native coronary artery lesions: A randomized comparison of a sirolimus-eluting stent with a standard stent for coronary revascularization. N Engl J Med 2002; 346: 1773-1780.

15. Sharma S, Bhambi B, Nyitray W. Sirolimus-eluting coronary stents. N Engl J Med 2002; 347: 1285.

16. Serruys PW, Unger F, Sousa JE, Jatene A, Bonnier HJ, Schonberger JP, et al. Comparison of coronary-artery bypass surgery and stenting for the treatment of multivessel disease. N Engl J Med 2001; 344: $1117-1124$

17. Rodriguez A, Bernardi V, Navia J, Baldi J, Grinfeld L, Martinez J, et al. Argentine Randomized Study: Coronary angioplasty with stenting versus coronary bypass surgery in patients with multiple-vessel disease (ERACI II): 30-day and one-year follow-up results: ERACI II Investigators. J Am Coll Cardiol 2001; 37: 51-58.

18. SoS Investigators. Coronary artery bypass surgery versus percutaneous coronary intervention with stent implantation in patients with multivessel coronary artery disease (the Stent or Surgery trial): A randomised controlled trial. Lancet 2002; 360: 965-970.

19. Reynolds MR, Neil N, Ho KK, Berezin R, Cosgrove RS, Lager RA, et al. Clinical and economic outcomes of multivessel coronary stenting compared with bypass surgery: A single-center US experience. Am Heart J 2003; 145: 334-342.

20. Bucher HC, Hengstler P, Schindler C, Guyatt GH. Percutaneous transluminal coronary angioplasty versus medical treatment for nonacute coronary heart disease: Meta-analysis of randomised controlled trials. BMJ 2000; 321: 73-77. 